after removal of rust showed that the ancient iron had suffered a loss amounting to 89 per cent of that of the modern steel. The specimens were then exposed to the action of an artificial seawater for a year and again the ancient iron lost less weight than the modern steel, losses being in the ratio $75: 100$. However, tests of this kind, made on single specimens, and including only one modern steel, really show very little about the corrosion resistance of the ancient metal.

\section{Miscellaneous Specimens}

The so-called Pillar of Heliodorus at Besnagar, which is itself of stone, is supported at its base by iron wedges which are still in a partial state of preservation. It is believed that the pillar was erected about 125 в.c. and that the iron supports were used from the outset. However, there is a possibility that the metal was not native India iron, but was imported from Greece. Hadfield has examined a sample of it and describes it ${ }^{\mathbf{1 2}}$ as the only ancient ferrous specimen which can be called steel; he actually demonstrated that it could be hardened by quenching. The structure was pearlitic, having elongated and irregularly disposed crystals of sorbitic pearlite upon a ferrite ground mass; after quenching from $850^{\circ} \mathrm{C}$. in water, a specimen became martensitic. There were seams of slag in some portions. Analysis showed C, 0.70 ; Si, 0.04 ; S, 0.008 ; P, 0.020 ; Mn, 0.02 ; Cr, a trace; Fe, 99 . The Brinell hardness number was 146.

W. Rosenhain ${ }^{13}$ mentions ancient iron chains which assisted pilgrims to climb Adam's Peak,
Ceylon. These have been worn round and smooth, but are apparently uncorroded. Rosenhain suggested that the links have corroded down to a cinder layer so that the outside remaining is apparently only a cinder surface protecting the iron below ; specimens cut and brought to London rusted as quickly as any other iron. Graves ${ }^{14}$ gives a list of 239 pieces of iron ranging up to 17 feet long and up to 6 inches by 4 inches section used in the construction of the Garden Temple at Puri, which was built not later than the first half of the twelfth century. However, no further information on these is available.

Iron swords and daggers of uncertain date have been unearthed from burial sites in the district of Tinnevelly and specimens of third century iron have been recovered from Buddha Gaya ${ }^{15}$ but no examination appears to have been made.

It seems possible that many specimens of iron exist in India of which the date of manufacture cannot be established, but which may well be ancient, and there are no doubt others of ascertainable date yet to be excavated from the earth.

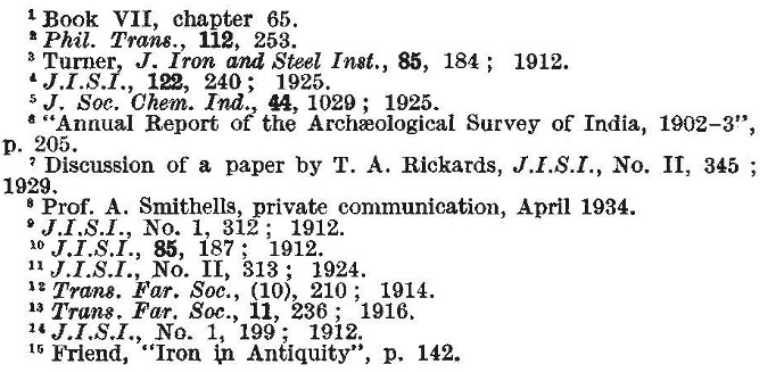

(To be continued.)

\title{
Samuel Pierpont Langley (I834-I906)
}

$\mathrm{O}^{\mathrm{N}}$ $\mathrm{N}$ August 22, the centenary of the birth of Samuel Pierpont Langley will be com. memorated at the Smithsonian Institution, Washington. Langley was secretary of the Institution from 1887 until 1906 ; it was there he made his valuable investigations in aeronautics and to him was due the inauguration of both the Astrophysical Observatory and the National Zoological Park, which, like the United States National Museum and the Bureau of American Ethnology, are integral parts of the Institution. Much of his experimental apparatus is preserved in the Museum, and it has accordingly been arranged for a special exhibit devoted to his activities and honours to be unveiled on the hundredth anniversary of his birth. The exhibit is being arranged by Mr. T. T. Belote, curator of the Division of American History, and it will ultimately be one of four recalling his own work and that of his two predecessors, Joseph Henry, who was secretary from 1846 until 1878, and Spencer Fullerton Baird, who held the office from 1878 until 1887, and of his successor, Charles Doolittle Walcott, who was secretary from 1907 until 1927. It is also intended to direct attention to Langley's work in the Press, and to publish a special memoir of him containing some extracts from his writings.

Langley was born at Roxbury, Massachusetts, on August 22, 1834, and died at the age of seventyone years on February 27, 1906, at Aiken, South Carolina. The son of a wholesale merchant of Boston, he came of a family connected with many of the most eminent men in the history of Massachusetts, and grew up in an atmosphere which stimulated his original and inquiring mind. Even as a mere child, he had the use of a telescope, and he once declared that he could not remember when he was not interested in astronomy. Like all the family, he was an omnivorous reader and when, as a youth of seventeen years, he left the Boston High School, he had laid the foundation of his knowledge of English, French and German classics. On leaving school he took up civil engineering and architecture, and at the age of twenty-three years went westward, spending seven years in Chicago and St. Louis. Of this 
phase in Langley's career, his biographers say very little.

The turning point in Langley's career came when he was thirty-one years of age. Following a tour in Europe, during which he visited many scientific institutions and observatories, he abandoned practical engineering for astronomy, and although without any academic standing, in 1865 he became an assistant in Harvard Observatory. In the following year he joined the Naval Academy at Annapolis as an assistant professor of mathematics and in 1867 was appointed director of the Allegheny Observatory and professor of physics in the Western University of Pennsylvania, Pittsburgh, where he remained twenty years. To this period belongs his important researches on the sun which brought him fame both at home and abroad. He took part in total solar eclipse expeditions to Kentucky in 1869 , to Spain in 1870, and to Pike's Peak in 1878, and a year or two later invented the bolometer, an electrical resistance thermometer of extreme delicacy. With this he was able to explore the infra-red portion of the sun's spectrum, and after experiments at Allegheny, with his assistant James Edward Keeler (18571900), afterwards director of Lick Observatory, made an expedition to Mount Whitney, California, where at a height of 14,887 ft. "in the driest and purest air, perhaps in the world . . . the known extent of the solar spectrum was thus at once more than doubled". While at Allegheny he also had a large share in inducing the railway companies to adopt the system of standard time now in use, and likewise became known as a lecturer and writer able to present difficult and abstruse subjects in language at once lucid and entertaining.

Many honours came to Langley through his study of solar radiation, and by the age of fifty years he had gained an international reputation. His connexion with the Smithsonian Institution began in January 1887, when he was appointed assistant secretary and placed in charge of the library and international exchanges. In that year he also served as president of the American Association for the Advancement of Science, and in November, on the death of Baird, was made secretary of the Smithsonian Institution. Though somewhat hampered by want of funds, with money from private sources he was able to establish the Astrophysical Observatory, and after three years of effort on his part, in 1890 Congress made an appropriation of 200,000 dollars for the purchase of 167 acres of land near Washington for a National Zoological Park.

The outstanding feature of Langley's life's work at Washington, however, was his devotion to the infant science of aeronautics, which then had many more sceptics than students. Like the experiments of his contemporaries-Lilienthal in Germany, Hargrave in Australia, Ader in France, and Maxim in England-Langley's investigations were made in comparative isolation and at the time attracted but little attention. Speaking in 1922, long after the aeroplane had become a commonplace, Prof. L. Bairstow referred to Langley's work as "a first rate example of systematic inquiry. . . . Progress was made step by step in the face of formidable difficulties, and no attempts were made to solve the problems of mechanical flight by bursts of brilliance or invention"

Langley's successful experiments with model aeroplanes are now well known, but there is another important aspect of his work. This is referred to in the sketch of Langley given in the "Dictionary of American Biography" now being published under the auspices of the American Council of Learned Societies. "The greatness of his contribution to aviation," the writer says, "depends not only on his pioneering laboratory investigations and successful long-distance flights of large power-driven models, but on the very fact that a man of his reputation should have adventured it in a field at that time so much ridiculed." The development of aviation was largely determined by his efforts, and the Wright brothers wrote that "the knowledge that the head of the most prominent scientific institution of America believed in the possibility of human flight was one of the influences which led us to undertake the preliminary investigations that preceded our active work".

The first fruits of Langley's laboratory investigations were given in his "Experiments in Aerodynamics" published in 1891 and "The Internal Work of the Wind" of 1893. Having discovered some of the fundamental principles underlying the design of heavier-than-air flying machines, he proceeded to construct power-driven models. After using twisted rubber and wound-up springs for driving the propellers, he constructed petrolheated flash-boiler steam engines weighing about 5 lb. per horse-power. His models he called "aerodromes", and on May 6, 1896, at Quantico on the Potomac, Aerodrome No. 5 flew some $3,000 \mathrm{ft}$. Six months later, on November 28, No. 6 flew 4,200 ft. These were the first sustained free flights of power-driven heavier-than-air machines ever made. Writing of what he had accomplished, Langley said a year or two later: "I have brought to a close the portion of the work which seemed especially mine-the demonstration of the practicability of mechanical flight-and for the next stage, which is the commercial and practical development of the idea, it is probable that the world may look to others. The world, indeed, would be supine if it does not realise that a new possibility has come to it, and that the great universal highway overhead is now soon. to be opened."

It does not appear from Langley's writings that he anticipated constructing a full-size aeroplane, but he was one of those who find themselves "in the river of the thoughts and events, forced onward by the ideas and necessities of his contemporaries". Through the suggestion of some American naval and military officers, the War 
Department Board of Ordnance in 1898, during the presidency of $\mathrm{Mr}$. McKinley, secured an appropriation of 50,000 dollars for the building of a man-carrying machine, and Langley at the age of sixty-four years found himself committed to a task which might well have daunted far younger men. As before, the power unit proved one of the greatest difficulties, but this problem was solved by the brilliant young inventor Charles Matthew Manly (1876-1927), who had been recommended to Langley by Prof. Thurston. After several attempts, Manly produced the five-cylinder radial petrol engine, now preserved at Washington, which was used in the abortive trials of 1903. The engine with its accessories weighed $187.47 \mathrm{lb}$. and developed 52.4 h.p. at 950 r.p.m. Manly was also the pilot on the trials of October 7 and December 8, 1903 , and on both occasions narrowly escaped drowning.
The failure of those trials was undoubtedly a great disappointment to Langley, but in the opinion of many well qualified to judge, only a little more good fortune would have secured for the Langley machine the record established a few days later at Kitty Hawk by the machine of Wilbur and Orville Wright. Of the trials of Langley's machine made in 1914 over Lake Keuka, at Hammondsport, New York, by Glenn Curtiss, some observations were made in NATURE of November 3, 1921, January 26, and March 9, 1922 , and it is unnecessary to repeat them here. Langley had passed away many years before those trials, leaving behind him a remarkable record of sustained effort and steady achievement, and of undiminished faith in the future of aviation. His record is indelibly inscribed in both the history of the study of the heavens and the story of the conquest of the air.

\section{The Loch Ness "Monster"}

GINCE our earlier notes upon this subject were D written (NATURE, Jan. 13, 1934, p. 56), the attention of thousands of people has been concentrated upon seeing and adding to the descriptions of this world-famous animal. The situation is without parallel in the records of the observation of Nature, and it is of some interest to analyse the results.

Clearly the recent records are not all of equal value. On July 4, a worker at Glendoe sawmill (as reported in the Scotsman, July 7) observed the creature emerge from the loch: as it emerged propelled by flippers, five humps were seen, twelve distinct humps as it wormed its way ashore, head smaller and thicker than a horse's, neck heavily maned, body fully 30 feet long, but not very thick. It was seen to feed upon weeds and water plants growing on the shore (a previous observer had seen it or another carrying a lamb in its mouth) and as the monastery clock struck 10 a.m., it wriggled back into the loch, having been under observation for an hour. A drawing representing this apparition accompanied the newspaper account.

In a different category must be placed the photograph, by Dr. R. K. Wilson, reproduced in the Daily Mail of April 21, of a long neck with small head projecting from the loch at a distance of 150-200 yards from the camera. The difficulty in this case is to convince oneself that the object photographed is a head and neck, and is movingthe indications on the water surface suggest rather a stationary object.

Undoubtedly the most thorough series of observations is that due to the organisation of Sir Edward Mountain, who for four weeks, just concluded, has had twenty watchers posted at points of advantage on the shores of Loch Ness. They report having seen the creature twenty-one times and have made five photographs. Three of the photographs, presumably the better ones, have been reproduced in different newspapers. Of these, one shows the wash of an object, probably bulky and moving at considerable speed, but of the object itself nothing. A second shows a very low dark 'hump' or perhaps two, but in the reproduction, lines, less marked, seem to be continued in both directions from the dark object, and a moving object does not make a wash in opposite directions. Even if this represents something animate, the something is indeterminate. The third reproduction (in the Scotsman) is more definite, showing something short and fairly massive, low in the water, succeeded by two or three less distinct 'humps'. It is impossible to say what it is, but it suggests to the writer the appearance of the head of a large seal, and the 'humps' water ripples caused by shoulders and hind quarters. Of the twenty-one reports, all that the published accounts (Times and Scotsman, August 9) say is that "in the main . . . the watchers agree that when on the surface the monster displays a very small head relative to the size of the body, and moves along the water in such a way as to show either two or three humps".

We write with the disadvantage of not having examined the negatives or the actual reports of Sir Edward Mountain's watchers (who presumably are untrained in the observation of animal ways), but keeping in mind that any creature of marine habit transported to fresh water, will lie low in the water and so lose some of its usual appearance, we do not yet find it necessary to depart from our earlier suggestion that the monster may be a large grey seal. The great difficulty is to account for the frequent descriptions of a small head on a long neck, but the reproduction in the Scotsman does not suggest a very small head (if the anterior portion showing is the head) and the summary of the observations of Sir Edward Mountain's watchers makes no mention of a long neck.

J. R. 